\title{
PONTO DE VISTA
}

\section{O futuro da prática gerencial}

Quais são os grandes desafios colocados às empresas brasileiras para se tornarem mais competitivas no cenário internacional? Para responder a essa questão, a GV-executivo convidou cinco profissionais com ampla e diversificada experiência na prática de gestão de empresas, consultoria organizacional e formação de executivos. Leonardo Toscano, Mário César M. de Camargo, Olga Colpo, Ulrico Barini Filho e Vicky Bloch fazem uma análise das principais lacunas de competitividade e de desenvolvimento de competências organizacionais e gerenciais presentes nas empresas brasileiras, e apontam alternativas para superação.

por Françoise Terzian

T omados em conjunto, os depoimentos aqui recolhidos abordam aspectos decisivos para o desenvolvimento da competitividade das empresas brasileiras. Dois deles mere cem destaque particular. 0 primeiro refere-se à lacuna cultural de nossos gestores, que se manifesta no grave desconhecimento da realidade local e nabaixa integração dos modelos dene- gócio e gestão correntes. E o segundo refere-seà qual ificação ainda incipiente de nossos executivos, em especial em termos de pensamento estratégico e habilidades de planejamento. 


\section{Vencer a lacuna cultural \\ Ulrico Barini Filho \\ Vice-presidente de Pessoas \\ e Organização da Braskem}

A primeira lacuna que nossas empresas têm de enfrentar para serem mais competitivas está relacionada à tecnologia de gestão. Temos orgul ho das empresas nacionais que são verdadeiras "ilhas de competitividade", mas a verdade é que a grande maioria delas ainda sofre com a baixa qualificação geral dos trabalhadores, com a fragilidade dos instrumentos de planejamento e com limitada capacidade de percepção gerencial. Isso tem influência sobre a produtividade, a qualidade dos produtos e serviços, e a capacidade de aprendizado das organizações.

Outra lacuna relevante refere-se à baixa capacidade de investimento e de atualização tecnológica de nossas

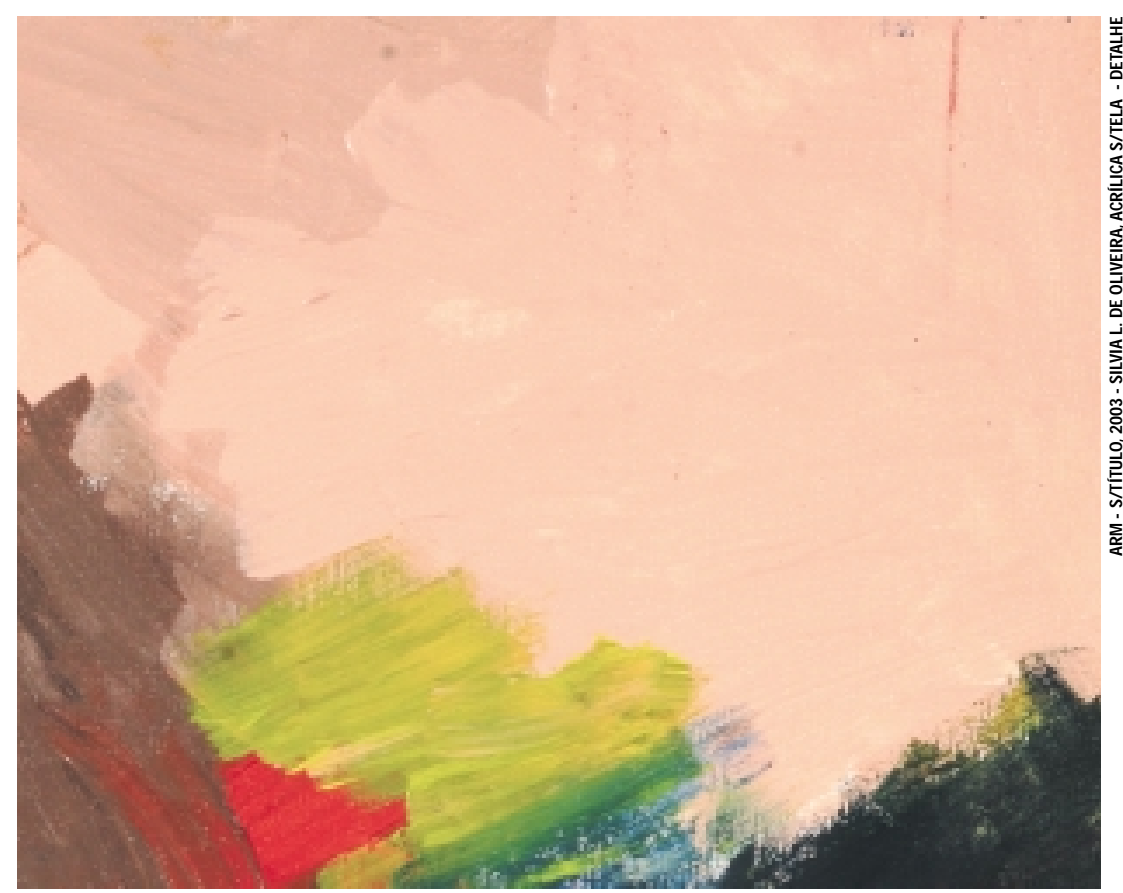

\section{É comum encontrarmos nas empresas brasileiras um corpo} gerencial pouco atualizado, praticando uma gestão de cunho doméstico ou familiar e sem visão estratégica, com uma concepção obsoleta da utilização de seus recursos humanos. empresas. Não é fácil competir globalmente quando se tem um al to custo relativo de capital e pequena capacidade de geração de tecnologias.

Uma terceira lacuna relaciona-se com nossa defasagem cultural. Ainda hoje sofremos com o isolamento a que fomos submetidos no passado. Ser competitivo em escala global parece algo muito difícil, epoucos empresários brasileiros conseguem perceber o valor de uma inserção global. E isso não se refere apenas à política industrial ou de exportação, mas também à visão de mundo do brasileiro médio, quer seja empresário, gerente ou especialista.

\section{empreendedores nascentes.}

Como superar essas lacunas? 0 primeiro aspecto a considerar é $o$ investimento na qualificação de nossos executivos, que ainda hoje sofrem com a dissociação entre o que se ensina nas escolas de Administração e o que se vivencia na realidade das organizações. Aproximar esses dois universos torna-se vital. 0 segundo aspecto é gerar uma maior valorização de nossas forças e competências, evitando a tendência de copiar modelos e processos caros e distantes das necessidades de nossas empresas. Por fim, o governo poderia fazer mais; um bom começo seria libertar as empresas de tantas amarras burocráticas e tributárias. 


\section{Desenvol vimento da} inteligência gerencial

Mário César M. de Camargo

Presidente da Gráfica Bandeirantes

e da Associação Brasileira da

Indústria Gráfica (Abigraf)

As lacunas de competitividade das empresas brasileiras, em comparação com as empresas estrangeiras, podem ser divididas em dois grupos, de natureza exógena e endógena. Com relação ao primeiro grupo, temos aspectos como a elevada carga tributária do

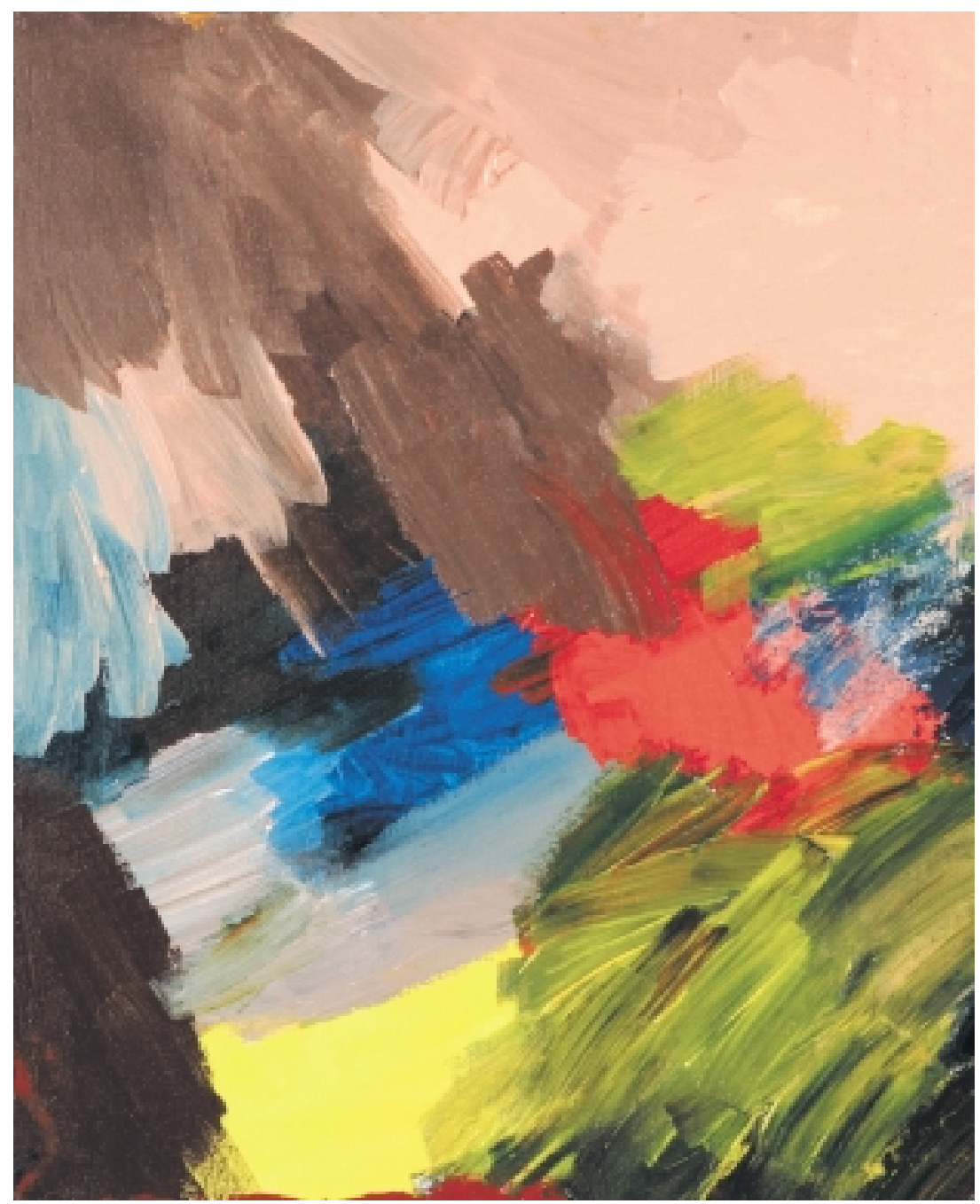

competência profissional. Houve, na última década, uma evolução sensível nos fatores de produtividade relacionados à tecnologia e equipamentos, mas essa evolução não foi acompanhada pelo correspondente desenvolvimento da qualificação profissional, em particular do corpo dirigente das organizações.

Como conseqüência, é comum encontrarmos um corpo gerencial pouco atualizado, praticando uma gestão de cunho doméstico ou familiar e sem visão estratégica, com uma concepção obsoleta da utilização de seus recursos humanos. 0 quadro é agravado se consideramos a existência de práticas comerciais desleais, baixo investimento em qualificação profissional eo desconhecimento, por parte desse mesmo corpo gerencial, das mais recentes técnicas de administração financeira.

Como lidar com essa situação? Penso que, antes de tudo, é preciso identificar a origem das deficiências. Por exemplo, no caso do setor gráfico, o foco está no corpo dirigente. Para resolver essa deficiência, estamos desenvolvendo o que denominamos "inteligência gerencial". Para isso, oferecemos cursos, seminários e promovemos debates, com o intuito de atingir todos os membros das organizações associadas, mas com especial atenção a seus dirigentes. Assim, esperamos capacitá-los em termos de maior visão estratégica. $A$ boa notícia é que a geração que sucede aos antigos fundadores parece estar mais bem preparada e capacitada, tanto em termos acadêmicos quanto em termos culturais. 


\section{A busca do equilíbrio}

Leonardo Toscano

Diretor Superintendente do Centro de Soluções Compartilhadas do Grupo Camargo Corrêa

Se, por um lado, as empresas brasileiras já se aproximaram dos concorrentes internacionais no que diz respeito ao uso de tecnologias e aos ganhos de produtividade, no campo do custo de capital e da gestão de riscos elas ainda estão bastante defasadas.

Com relação ao custo de capital, o quadro agravou-se nestes últimos 10 anos. Houve um expressivo aumento da taxa de juros, da burocracia governamental, da quantidade de barreiras institucionais e da carga tributária em geral.

Quanto à gestão de riscos, as empresas brasileiras, com notáveis exceções, ainda não incorporaram por completo a necessidade de um pensamento de longo prazo, isto é, de maior planejamento. A conseqüência direta se faz sentir na dificuldade que muitas empresas têm para praticar mecanismos apropriados de medição, interpretação e mitigação de riscos.

Esse cenário traz desafios impor-

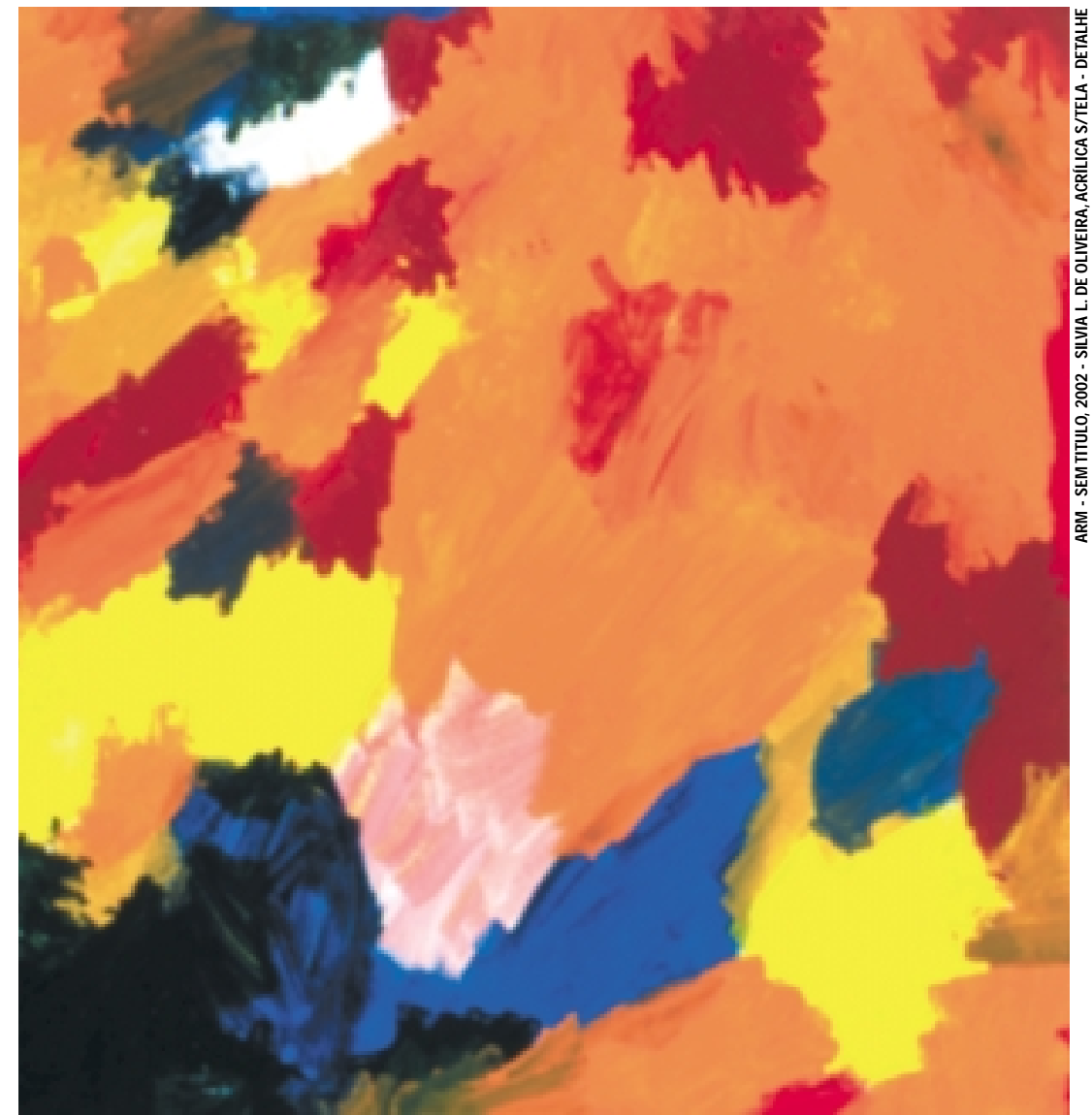

tantes. 0 primeiro deles é promover um ambiente voltado à alta performance. Isso envolve um claro direcionamento estratégico, uma rígida disciplina de medição e acompanhamento de resultados, o desenvolvimento de ferramentas de melhorias

\section{Temos orgulho das empresas nacionais que são verdadeiras} "ilhas de competitividade", mas a verdade é que a grande maioria delas ainda sofre com a baixa qualificação dos trabalhadores, com a fragilidade dos instrumentos de planejamento e controle, e com limitada capacidade de percepção gerencial. contínuas e de planos de recompensas bem desenhados, que respeitem os profissionais na medida exata de sua contribuição para a geração de valor às empresas.

0 segundo desafio é promover uma combinação saudável entre o velho e o novo, o tradicional e o inovador, o caro e o barato, o nacional e 0 internacional. 0 equilíbrio é fundamental para que as empresas brasileiras consigam realizar uma gestão que fuja de excessos e exageros. Esse equilíbrio deve ser estendido a praticamente todas as instâncias da gestão do negócio, como aos recursos humanos, equipamentos, produtos, políticas e tecnologia. 


\section{Identificar e desenvolver competências \\ Olga S. Colpo \\ Sócia da PricewaterhouseC oopers}

Em um contexto em que o padrão de excelência das empresas passou a ser medido com referências globais, - gerenciamento contínuo do trinômio qual idade, preço e serviços tornou-se o desafio maior para as organizações do mundo inteiro, e o mesmo se verifica com as empresas brasileiras. Como resultado, a gestão é elevada ao primeiro lugar na pirâmide das necessidades organizacionais. Assim, devemos nos perguntar como estão nossas empresas em termos de gestão. $E$, na verdade, nessa dimensão ainda temos muito a desenvolver.

Como exemplo, tomemos o conceito de competência organizacional, essencial para a construção de mo- delos consistentes de gestão. Ninguém hoje questiona o fato de que as empresas, para serem bem-sucedidas, precisam dominar um conjunto adequado de competências referentes ao negócio e às pessoas. $\mathrm{No}$ entanto, uma rápida passagem pelo cotidiano de muitas empresas brasileiras mostrará um quadro muito aquém do que seria adequado.

De fato, poucas organizações conseguem desenvolver estratégias ou ferramentas para identificar as competências fundamentais para a geração de resultados diferenciados e, portanto, para sustentar uma vantagem competitiva de médio ou longo prazo. Mesmo quando conseguem, as dificuldades permanecem. Há dificuldades para administrar a evolução das competências, para priorizá-las e para renová-las.

0 futuro acena para a necessidade de as empresas brasileiras centra- rem melhor seus esforços na gestão de pessoas, com base nas competências. Tal perspectiva poderá assegurar um bom resultado para o trabalho e um futuro promissor para as organizações. Mas o que precisa exatamente ser feito? De forma objetiva, o que precisamos é desenvolver um modelo profissionalizado de competências, integrado ao modelo de gestão e de negócios.

Para isso, tal desenvolvimento deve incluir três aspectos centrais. Primeiro, a identificação das competências essenciais, usualmente relacionadas ao núcleo da estratégia do negócio e aos valores que devem ser praticados no cotidiano da gestão. Segundo, a promoção de conhecimentos, experiências, habilidades e atitudes necessárias à gestão dos recursos. E, por fim, é preciso focar a atividade-fim da empresa, não perdendo de vista a necessidade de se atingir a máxima eficácia operacional.

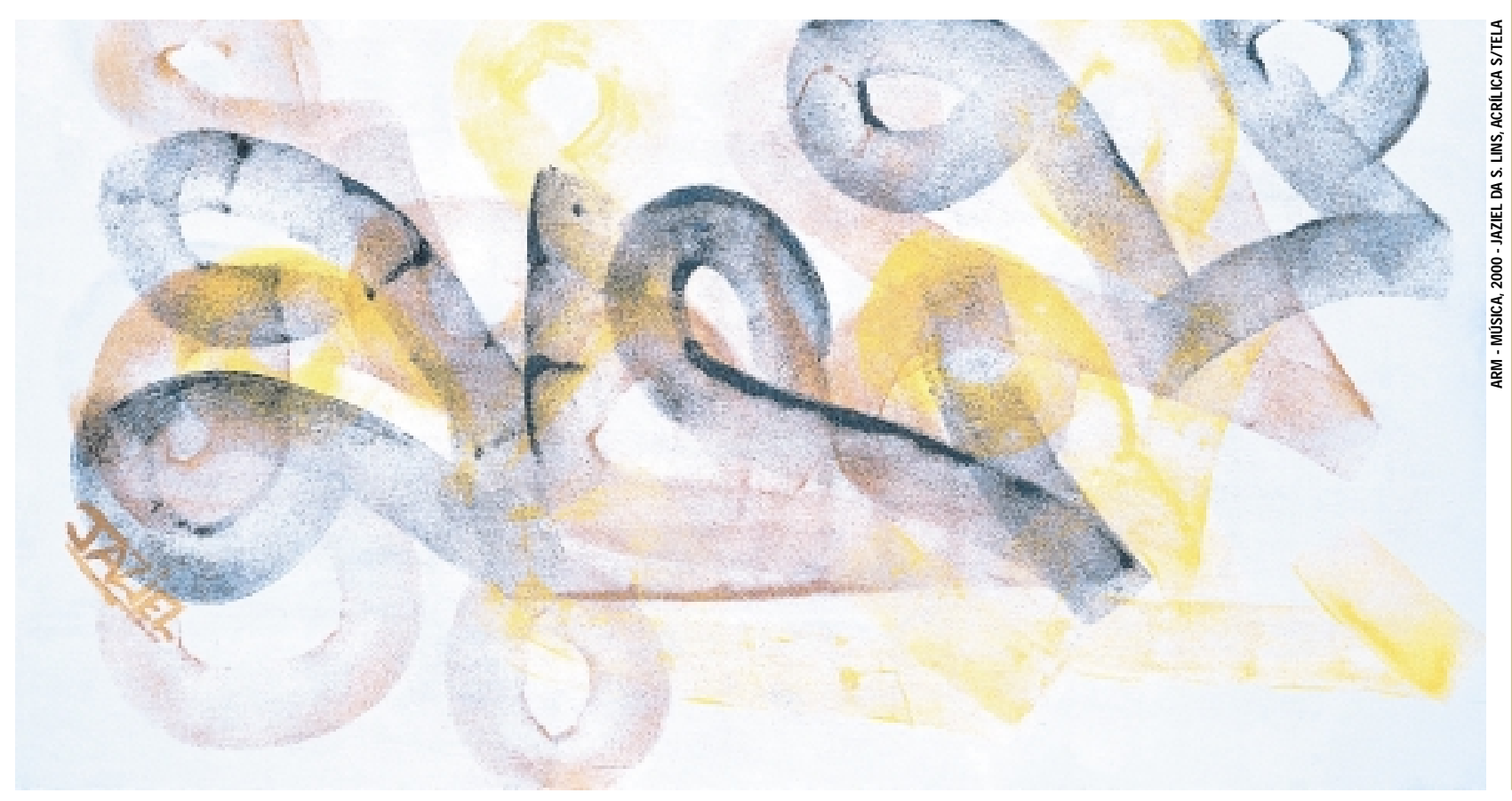




\section{Acel eração do amadureci men- to dos jovens profissionais}

Vicky Bloch

Diretora-executiva da DBM do

Brasil e Presidente Regional para a

América Latina

São inúmeros os desafios das empresas brasileiras na formação de seus executivos. De todos eles, no entanto, a aceleração exigida pelas empresas na maturação dos jovens que estão ingressando no mercado de trabalho é o desafio principal. Esperase que 0 jovem profissional produza e gere resultados tão logo se forme, e que não leve um tempo muito longo para adquirir a experiência e o conhecimento necessários a uma atuação profissional sólida e equilibrada.

$E$ as exigências se tornam cada vez maiores. Por exemplo, as empresas buscam indivíduos com elevada capacidade para comandar grupos de funcionários, bem como capazes de lidar com as ambigüidades, conflitos e contradições presentes em ambientes organizacionais cada vez mais complexos. Evidentemente, tudo isso deve acontecer num ritmo que não coincide necessariamente com o ritmo de desenvolvimento emocional e intelectual de muitos desses novos profissionais.

A idade média de formação de nossos jovens ocorrehoje por volta dos 21-23 anos. Nessa idade, muitos aspectos da carreira ainda não estão sedimentados. Para agravar a situação, as próprias faculdades não estão pre paradas para formar esses jovens num sentido mais abrangente. Em primeiro lugar, muitas delas estão defasadas

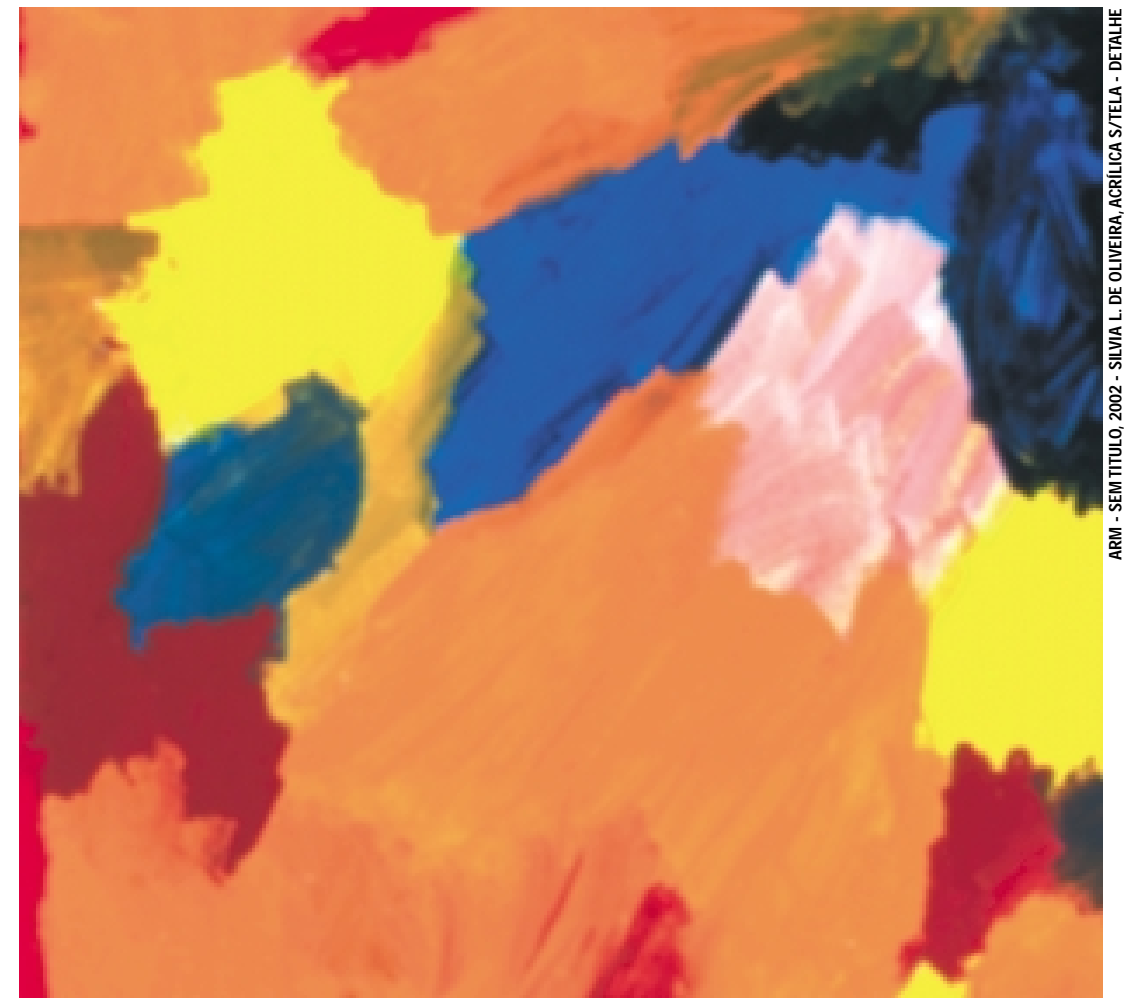

com relação à realidade vivida pelas empresas. Os programas atuais de estágio mais se assemelham a arranjos precários de empregos e serviços baratos do que a atividades planejadas de formação profissional. Em segundo lugar, a ênfase de muitos cursos recai basicamente sobre os aspectos cognitivos da aprendizagem, e não sobre questões de desenvolvimento emocional, tão importantes para a formação integrada do profissional.

Como reverter esse quadro? A premissa central é que um executivo precisa ser preparado desde o início, e com tempo. Um desenvolvimento ideal deveria incluir cursos de graduação universitária que se orientassem por atividades próximas à realidade das empresas. 0 curso deveria funcionar como um tipo de labo- ratório de experimentação das competências exigidas no desenvolvimento das carreiras desses jovens, seguido de estágios efetivos, que realmente construíssem uma ponte necessária entre o mundo organizacional e o mundo acadêmico. Outro aspecto importante é que as empresas também devem cumprir sua parte. Elas poderiam, por exemplo, oferecer programas de trainee que possibilitassem o exercício de competências gerenciais, com o apoio de mentores realmente comprometidos com o desenvolvimento desses novos profissionais.

Françoise Terzian

Jornalista

E-mail: francoiseterzian@uol.com.br 